\title{
Waste to Energy Technology Management, the most sustainable and efficient Waste Management approach in the Sub-Saharan Africa: Case Study of Cosmopolitan Regions
}

\author{
Jeffery Okere Afriyie \\ University of Energy and Natural Resources (UENR), Sunyani
}

\begin{abstract}
:
The clarion call for Waste to Energy Technology is gaining momentum in Sub-Saharan Africa as it is gradually becoming the surest bet for clean energy and wealth creation. According to the Zoomlion Alliance Africa (2017 Index Report) close to 900,000MT of both Solid and Liquid wastes are generated per each Cosmopolitan region half yearly. These wastes are left to the dictates of nature which add up to the ongoing climatic changes in the form of rise in sea levels as $70 \%$ of these waste materials find their route into sea bodies. Waste (also known as rubbish, refuse, garbage) is unwanted or useless materials. Solid wastes are from municipal, industrial, and agricultural activities. However, any refuse or waste can be an economic resource to others depending on the application of the rightful technologies with Waste to Energy Technology (WTE) as the most tried and tested in the Asian Regions. Waste is just value that we are too stupid not to use (Albert Einstein). Solid waste (SW) is an environmental and public health problem. There is a sustainable management method for Solid Waste. Uncontrolled landfill gases have negative health impacts on the local populace. Sorting Solid Waste increases its ability to be repurposed. Solid Waste is a cost-effective renewable energy source. Examples of Solid Waste includes Wood residuals from lumber mills (off-cuts, sawdust), Expired trees, Agricultural waste and Sorted municipal wastes (plastic, paper). Project assumptions of setting up a successful Waste to Energy Technology is estimated at an Installed capacity cost of: \$4,500,000 Includes equipment, shipping, customs and installation, Annual Operations and Administrative cost of $\$ 250,000$. The Project useful lifetime is 20 years, Electricity generation: 7,560 MWh, Price of $1 \mathrm{kWh}$ to national grid = USD 0.15 and the Cost of acquiring $1 \mathrm{kWh}$ worth of waste $=$ USD 0.01 . These facts make Waste to Energy Technologies not only reliable but cost effective and efficient.
\end{abstract}


International Academic Conference on Management \& Economics

\section{Methods:}

Data from the Directorates of 17 Sanitation Ministries in Africa for the years 2012-2017 were used. Chi-square test and Logistic Regression Model were used to evaluate the relationship between usage of technologies and waste management.

\section{Results:}

94.6\% of Cosmopolitan Government Structures still ready to resort to waste to Energy Technologies only $5.4 \%$ has instituted appropriate advanced technologies on waste to energy. This is mostly called the Waste to Energy Projects (WTE Projects). The upscale of these waste to energy technologies has the propensity of creating sustainable wealth, reducing more filthinduced sicknesses and mostly importantly create worth.

Estimately, close to $23 \%$ of Health budgets of most Governments in the Sub-Saharan Africa goes into filth induced sickness. This implies that adopting the needful technologies in waste management will end not only creating wealth but undeniably create a more healthy Sub-Saharan Africa. Most Cities have become a confused web of disorganized human activities where the life somehow moves within squalid, filthy and shabby urban envelop caused by overcrowding, insanitary environment, the heterogeneous mixture of non-conforming functions.

Conclusion: Waste to Energy must be embraced by many Sub-Saharan African Countries not only as creating a clean energy but riding our Cosmopolitan areas of needless filth. This has impact on urban sustainability.

Keywords: Agricultural waste and Sorted municipal wastes; Clean Energy; Climatic Changes; Logistic Regression, Urban sustainability. 